\title{
Are clinicians being prepared to care for abused women? A survey of health professional education in Ontario, Canada C Nadine Wathen*1, Masako Tanaka ${ }^{2}$, Cristina Catallo ${ }^{3}$, Adrianne C Lebner ${ }^{4}$, M Kinneret Friedman ${ }^{5}$, Mark D Hanson ${ }^{2}$, Clare Freeman ${ }^{6}$, Susan M Jack ${ }^{3}$, Ellen Jamieson'2, Harriet L MacMillan ${ }^{2,7}$ for the McMaster IPV Education Research Team
}

\author{
Address: ${ }^{1}$ Faculty of Information \& Media Studies, The University of Western Ontario, London, Ontario, Canada, ${ }^{2}$ Department of Psychiatry and \\ Behavioural Neurosciences, McMaster University, Hamilton, Ontario, Canada, ${ }^{3}$ School of Nursing, McMaster University, Hamilton, Ontario, \\ Canada, ${ }^{4}$ Faculty of Health Sciences, McMaster University, Hamilton, Ontario, Canada, ${ }^{5}$ Michael G. DeGroote School of Medicine, McMaster \\ University, Hamilton, Ontario, Canada, ${ }^{6}$ Interval House of Hamilton-Wentworth, Hamilton, Ontario, Canada and ${ }^{7}$ Departments of Pediatrics, \\ McMaster University, Hamilton, Ontario, Canada \\ Email: C Nadine Wathen* - nwathen@uwo.ca; Masako Tanaka - tanakam@mcmaster.ca; Cristina Catallo - catallc@mcmaster.ca; \\ Adrianne C Lebner - ADRIANNE.C.LEBNER@learnlink.mcmaster.ca; M Kinneret Friedman - meri.friedman@medportal.ca; \\ Mark D Hanson - hansonm@mcmaster.ca; Clare Freeman - clareih@mountaincable.net; Susan M Jack - jacksm@mcmaster.ca; \\ Ellen Jamieson - jamie@mcmaster.ca; Harriet L MacMillan - macmilnh@mcmaster.ca; the McMaster IPV Education Research \\ Team - TheNET@mcmaster.ca \\ * Corresponding author
}

Published: 18 June 2009

BMC Medical Education 2009, 9:34 doi:10.1 186/1472-6920-9-34

This article is available from: http://www.biomedcentral.com/l472-6920/9/34

(c) 2009 Wathen et al; licensee BioMed Central Ltd.

This is an Open Access article distributed under the terms of the Creative Commons Attribution License (http://creativecommons.org/licenses/by/2.0), which permits unrestricted use, distribution, and reproduction in any medium, provided the original work is properly cited.

\begin{abstract}
Background: The current project undertook a province-wide survey and environmental scan of educational opportunities available to future health care providers on the topic of intimate partner violence (IPV) against women.

Methods: A team of experts identified university and college programs in Ontario, Canada as potential providers of IPV education to students in health care professions at the undergraduate and post-graduate levels. A telephone survey with contacts representing these programs was conducted between October 2005 and March 2006. The survey asked whether IPV-specific education was provided to learners, and if so, how and by whom.

Results: In total, 222 eligible programs in dentistry, medicine, nursing and other allied health professions were surveyed, and $95 \%$ (2/2/222) of programs responded. Of these, 57\% reported offering some form of IPV-specific education, with undergraduate nursing $(83 \%)$ and allied health $(82 \%)$ programs having the highest rates. Fewer than half of undergraduate medical $(43 \%)$ and dentistry (46\%) programs offered IPV content. Postgraduate programs ranged from no IPV content provision (dentistry) to $41 \%$ offering content (nursing).

Conclusion: Significant variability exists across program areas regarding the methods for IPV education, its delivery and evaluation. The results of this project highlight that expectations for an active and consistent response by health care professionals to women experiencing the effects of violence may not match the realities of professional preparation.
\end{abstract}




\section{Background}

Almost one in ten women in North America are physically abused by an intimate partner in any given year, and up to a third of women in population-based surveys report some form of physical or emotional abuse over the course of their lifetime [1-3]. Women exposed to intimate partner violence (IPV) suffer significant acute and chronic physical and mental health outcomes, including death, injury, chronic pain, poor gynaecologic and general health outcomes [4-6], posttraumatic stress disorder, depression, anxiety and substance abuse [5,7-9]. Women who experience violence use more health care services [10-12] yet are at risk for marginalization in the health care system due to the complexity of their physical and mental health needs [13].

In the face of this often overwhelming problem, the health sector has been identified as having a key role in identifying and responding to abused women [14,15], and, despite ongoing debate regarding the evidence for effective clinical responses [16-18], health care providers (HCPs) across the spectrum of disciplines are increasingly encouraged to ask about exposure to violence as part of their routine care of women, especially when clinical indicators of abuse are present [9,19].

The health sector, however, has been criticized for providing less than optimal care to women exposed to IPV. As Alpert [20] states " [t]he ability of most health professionals to effectively identify, assess, and respond to domestic violence has lagged far behind societal awareness and community responses" (p. 666). This is in part due to HCP perceptions that abuse is rare in their practice or that IPV identification and referral are not part of their role or responsibilities [21], as well as specific barriers to addressing IPV, including: lack of time to deal with a complex social issue; a fear of offending patients or retribution from the abuser; personal experiences with family violence; feeling helpless when clients disclose/experience violence; and not knowing how to recognize, ask about and respond to IPV [20-27]. These barriers, many of which can be attributed to lack of education and training, affect the HCP's confidence in her/his ability to provide appropriate responses to women experiencing violence [21]. Though the relative lack of well-conducted evaluative research assessing the impact of IPV education on clinical knowledge, skills and practices remains a pressing gap [27], current research does suggest an association between IPV training and clinical behaviour [28]. A survey of over 900 nurses and physicians in Ontario, Canada found that formal training in IPV was significantly related to whether they routinely initiated discussions about IPV with patients, and yet almost $60 \%$ in both professions reported never having received such education [29].
Trends in IPV education have been described based on surveys of U.S. and Canadian medical and nursing schools. In a 1989 survey of 116 US and Canadian medical schools regarding training about all types of adult domestic violence [27], the Centers for Disease Control and Prevention (CDC) found that 53\% of respondents did not offer any training while $42 \%$ offered training as part of at least one required course. Approximately ten years later, Alpert et al. [30] surveyed medical school deans and students from across the US and found that at that time, $60 \%$ of respondents reported course offerings on IPV. However, while increases in the number of schools providing some IPV education is a positive step, these surveys do not provide in-depth information on the type and extent of content provided to learners. In a survey of Canadian nursing schools $(n=155)$, the topic of IPV did not receive as many scheduled hours of instruction in the curriculum as child abuse and suicide [31], which was consistent with findings in a US study [32]. While there are emerging trends in the use of more integrative alternatives to primarily lecture-based pedagogy [33-36], such as problem-based learning, the usual approach to IPV education, certainly in medical schools, has been stand-alone lectures not truly integrated into important clinical training experiences [30]. For example, in the Canadian survey by Ross et al. [31] there was little indication of planned clinical experiences related to IPV.

Evaluative data regarding IPV education in allied health professional programs is lacking, and a quasi-systematic review by the Institute of Medicine's Committee on Training Needs of Health Professionals to Respond to Family Violence [37] concludes that across health professions " [i]n formal curricula on family violence, content is incomplete, instruction time is generally minimal, content and teaching methods vary, and the issue is not well integrated throughout the educational experience" (p. 44).

The surveys described above demonstrate that while there is some increase in IPV education in undergraduate health care professional programs, barriers persist to the implementation and evaluation of such training. These barriers include lack of institutional endorsement, lack of funding to support new curriculum, and competition for curricular time between and within departments [38].

Advocates of a more consistent and comprehensive response by the health sector to abused women have argued that all HCPs interacting with women should be prepared to recognize, inquire about and respond to cases of abuse [37]. To better understand whether and how HCPs are prepared in this area, the current project surveyed HCP undergraduate and post-graduate educational programs in Ontario, Canada. 


\section{Methods \\ Setting and Definitions}

Ontario is a Canadian province of over 12.5 million people with a publicly funded health care system that allocates about CDN\$35 billion per year for health services, including over 150 hospitals, 22,000 practicing physicians, 140,000 nurses, and over 40,000 practitioners registered in the allied health professions we surveyed. It has 18 publicly funded universities, 6 with medical schools (5 at the time of this study) and 24 colleges of applied arts and technology. ${ }^{\mathrm{i}}$ For clarity, and consistent with the way these programs are generally considered in Canadian universities, primary degrees obtained in medicine (MD), nursing $(\mathrm{BScN})$ and allied professions such as occupational and physical therapy (BSc(OT) and $\mathrm{BSc}(\mathrm{PT}))$ are considered as "undergraduate" while training beyond the primary professional designation (e.g., $\mathrm{MScN}$, residency programs, etc.) are considered "post-graduate" education. College-level degrees and diplomas were also considered "undergraduate" education.

\section{Sampling and Procedures}

All potential university and college programs in relevant areas (Table 1) were identified and a database of potential respondents created. A number of programs within a university or college were often grouped under one of our "program types" (e.g., undergraduate allied health programs included midwifery, $\mathrm{BScN}$ and occupational therapy, undergraduate medical programs included the general MD program, including both pre-clerkship and clerkship curricula). Results are presented using the following groups: allied health, dentistry, medicine and nursing.

For each program, individuals with sufficient knowledge of the curriculum to complete the survey were identified as eligible respondents. In October 2005, all respondents were mailed a survey with an invitation to participate in a brief telephone interview. Trained interviewers then contacted respondents by telephone, inviting them to schedule an interview time. The telephone survey involved use of a standard, scripted version of the survey. If the participant did not respond to initial follow up, a multi-modal follow up method based on Dillman [39] was implemented using mail, email and telephone.

On occasion, multiple respondents were identified. For example, when considering a specific program, there may have been several individuals who could have been interviewed, including the Dean, the Assistant Dean, the Director and the Program Coordinator. All of these individuals were sent a survey and contacted for follow-up, but it was generally only the Program Coordinator, knowing enough detail regarding elements of the curriculum, who was designated by the program to complete the survey. The unit of analysis for response rate calculations and descriptive statistics, therefore, was the individual program, not the number of surveys sent.

When a respondent was not aware of IPV-related educational initiatives in their program, they were asked to recommend another individual who could answer on the program's behalf. On many occasions, respondents provided a number of contacts, all of whom were followed up by interview staff. In cases where more than one person contributed to completion of the survey for a specific program, this was still counted as one completed survey. When inconsistencies arose among respondents, the interviewer conducted further interviewing until consensus was achieved.

Interviews were conducted from October 2005 to March 2006. The majority were completed by telephone and

Table I: Description of Surveyed Program Types

\begin{tabular}{|c|c|c|}
\hline Program Type & Level & Description \\
\hline Allied Health & UG & $\begin{array}{l}\text { University midwifery baccalaureate programs, social work baccalaureate and physical and occupational therapy } \\
\text { baccalaureate programs. For colleges this includes social service worker programs, child and youth worker programs, } \\
\text { aboriginal social service programs, police service worker programs. }\end{array}$ \\
\hline Allied Health & PG & Masters/PhD programs for social work, psychology, physical and occupational therapy \\
\hline Dentistry & UG & Doctor of dental surgery (DDS) degree and college-based dental hygiene programs. \\
\hline Dentistry & PG & $\begin{array}{l}\text { Specialty/residency areas for dentistry such as oral and maxillofacial surgery, prosthodontics, public health, and forensic } \\
\text { dentistry. }\end{array}$ \\
\hline Medicine & UG & All medical doctor (MD) degree programs. \\
\hline Medicine & PG & $\begin{array}{l}\text { Specialty/residency areas for medicine including: family medicine, psychiatry, pediatrics, emergency medicine, surgery, } \\
\text { obstetrics and gynecology, internal medicine and community health. MD/PhD programs for these medical specialties } \\
\text { were also included. }\end{array}$ \\
\hline Nursing & UG & $\begin{array}{l}\text { For the general classification of Registered Nurse }(\mathrm{RN}) \text {, this includes baccalaureate programs, combined/collaborative } \\
\text { college/university baccalaureate programs, and post-RN to baccalaureate programs. For training of Registered Practical } \\
\text { Nurses, college programs for practical nursing were included. }\end{array}$ \\
\hline Nursing & PG & $\begin{array}{l}\text { For extended classification (Nurse Practitioner), this includes all primary and acute Nurse Practitioner programs, } \\
\text { Masters and PhD programs in nursing and health sciences and all continuing education and certification offered at } \\
\text { colleges or universities. }\end{array}$ \\
\hline
\end{tabular}

UG = undergraduate; $P G=$ postgraduate 
lasted from 15 to 45 minutes. Five respondents completed their survey by mail; they were then contacted by phone by an interviewer to review their responses for any additional information. Programs were also asked to send copies of, or otherwise provide access to, any written course descriptions or formal policies or other curricular documents specific to IPV education. Ethical approval for this study was deemed unnecessary by the Research Ethics Board of McMaster University.

\section{Survey Instrument}

The survey instrument [see Additional file 1] was developed by the research team, with input from IPV and methods experts, to assess whether and how IPV education was offered. More specifically, the survey first inquired whether IPV-related education was offered and if so, how this was done (e.g., as a required course, clinical practicum, etc.), by whom, and with what resources. Additional questions asked about: specific IPV content; acknowledgement for completing training; integrating IPV content into the overall curriculum; facilitators and barriers to IPV content delivery; and existing evaluation strategies to assess the quality of this education. The questions were generally closed-ended, with the list of answers read to the respondent; however most questions included an "other" category where respondents could provide answers outside the scope of those listed; the interviewer also asked an open-ended question soliciting additional comments on each question and noted responses in a space provided on the form. To ensure completeness and usability and determine approximate administration time, the survey was pilot-tested with a group of university/collegebased program administrators in local programs that did not meet inclusion criteria for the study (i.e., were not in the specified health and allied health education areas). Adjustments to the instrument and/or the telephone survey process were made accordingly.

\section{Data Analysis}

Survey responses were entered into a Microsoft Access database, which was then imported into SPSS Version
12.0 for generation of the descriptive statistics reported here. All data were entered by one research assistant and verified by two others prior to analysis. Any uncertainties in data entry were resolved through consensus after reviewing the initial data collection forms and, if necessary, discussing the data with the interviewer who conducted that interview. As the goal of this project was to describe the provision of IPV education to future HCPs in Ontario, the focus was on providing descriptive summaries of the data.

\section{Results}

\section{Provision of IPV Education}

Table 2 shows the response rates for each program type. Overall, $95 \%$ of eligible programs responded to the survey (range $88 \%$ to $100 \%$ ). Table 2 also summarizes responses, by program type, to the primary question regarding provision of IPV education, with $57 \%(n=120)$ of the responding sample indicating that at least some IPV education was being offered at the time of the survey. The findings described below relate to specific aspects of IPV education based on information from programs that responded "yes" to the IPV provision question, and included programs from all types except postgraduate dentistry.

Across program types the following content areas were generally covered by over $85 \%$ of responding programs: overview of IPV, risks for IPV, characteristics of victims and perpetrators, methods for identification of IPV, interventions, and availability of and access to community resources. At the level of individual programs, these content types were generally provided by over $80 \%$ of programs, with the only outlier being the undergraduate dentistry programs. A third or fewer of responding programs indicated that they covered the topics related to risks, characteristics, identification or intervention; however all of these programs provided an overview and discussed community resources.

Table 2: Response Rate and Provision of IPV Education by Program Type

\begin{tabular}{llccc}
\hline Program Type & Level & Eligible programs sent survey N & $\begin{array}{c}\text { Programs responding to } \\
\text { survey \% (n) }\end{array}$ & $\begin{array}{c}\text { Programs providing IPV } \\
\text { education \% (n) }\end{array}$ \\
\hline Allied Health & UG & & $98 \%(65)$ & $82 \%(53)$ \\
Allied Health & PG & 66 & $94 \%(32)$ & $28 \%(9)$ \\
Dentistry & UG & 34 & $100 \%(13)$ & $46 \%(6)$ \\
Dentistry & PG & 13 & $100 \%(2)$ & $0 \%(0)$ \\
Medicine & UG & 2 & $88 \%(7)$ & $43 \%(3)$ \\
Medicine & PG & 8 & $92 \%(36)$ & $25 \%(9)$ \\
Nursing & UG & 39 & $98 \%(40)$ & $83 \%(33)$ \\
Nursing & PG & 41 & $89 \%(17)$ & $41 \%(7)$ \\
Total & UG & 19 & $\mathbf{9 8 \% ( 1 2 5 )}$ & $\mathbf{7 6 \% ( 9 5 )}$ \\
Total & PG & $\mathbf{1 2 8}$ & $\mathbf{9 3 \% ( 8 7 )}$ & $\mathbf{2 8 . 7 \% ( 2 5 )}$ \\
\multicolumn{2}{c}{ Grand Total } & $\mathbf{9 4}$ & $\mathbf{9 5 \% ( 2 1 2 )}$ & $\mathbf{5 7 \% ( 1 2 0 )}$ \\
\hline
\end{tabular}

UG = undergraduate; $P G$ = postgraduate 
Regarding time spent on IPV content, respondents indicated that an average of one to four hours was spent covering each of the content categories described above, as well as models, frameworks and theories that examine IPV, gender, multicultural and indigenous groups, and, to a lesser extent (i.e., averaging less than one hour), issues specific to violence by women against men, violence in same sex relationships, and common couple violence.

We also assessed how IPV content is provided, that is, whether it is included in required or elective courses (or other approaches) and what teaching techniques are used to deliver the content. Table 3 shows that IPV content is rarely delivered within required or elective courses or practica dedicated solely to IPV. Rather, it was often a component of a required or elective course, or delivered by other means, primarily through workshops, and, to a lesser extent, through distance education, online materials, or video-conferencing. In terms of credit for this content, $69 \%(81 / 117,3$ no response) of all program areas reported providing at least some form of credit or acknowledgement to learners upon completion of IPVrelated education, with the majority of programs offering partial credit (i.e., credit given for a course in which IPV content was a component). Postgraduate nursing (43\%, or $3 / 7)$ and undergraduate allied health (36\% or $18 / 51,2$ no response) programs were notable in that over a third of these types of programs offered a full course credit specific to IPV content. Over 30\% (35/117, 3 no response) of respondents across all program areas reported that no course credit or acknowledgement was offered.

Table 4 presents the teaching methods used by those who responded to this question (approximately one-third of programs did not respond to this item). In this case, standardized patients referred to actors paid to perform the role of a patient so that students may practice clinical skills. These are differentiated from simulated learning experiences, which included case study, role play and interviewing. IPV-related resources included audio visual (AV) materials, texts and/or learning kits.

\section{Resources for Delivering IPV Content}

We asked respondents to indicate what type of faculty (full-time, part-time, sessional or external experts) delivered IPV content to learners. Key findings include that most programs (84\%), with the exception of postgraduate nursing (43\%), have primarily full-time faculty teaching IPV content. Overall, 38\% of programs used part-time faculty (range $32 \%$ to $56 \%$ ). The greatest proportion of sessional or contract faculty utilized for this content was found in the allied health undergraduate (41\%) and postgraduate $(56 \%)$ programs. All programs reported some use of experts in the area to deliver content (range 17\% to $57 \%$, mean $49 \%$ ).

Table 5 summarizes some of the key resources we asked about regarding delivery of IPV content. In addition to these resources; $67.5 \%$ of respondents indicated that written policies, procedures, curricula or syllabi regarding IPVrelated education existed; $79 \%$ reported some form of extra-organizational collaboration (i.e., IPV or non-IPV related), and $62 \%$ reported collaboration regarding IPV education specifically.

\section{Factors Influencing Delivery of IPV Education}

We asked respondents about 'internal' influences within their faculty or department and 'external' influences outside their faculty or department that impacted the provision of IPV-related education. Results across program areas are presented in Table 6. Of note, an issue across program types, both internally and externally, was availability of funding for IPV education. Also, time available within the curriculum was likely to be identified as an internal barrier to delivery of IPV education across programs and in particular across graduate-level programs.

\section{Evaluation}

Respondents were asked whether and how they evaluated learners' acquisition of the IPV content. Overall, 59\% (71/ 120,38 missing) reported that they assessed what students learned from the IPV curriculum. The most common approach (72\% of programs) used a test or examination that including IPV-related questions. Other approaches included learner self-evaluation (28\%), a gen-

Table 3: IPV Education Delivery Methods

\begin{tabular}{|c|c|c|c|c|c|c|}
\hline Program Type & Level & $\begin{array}{c}\text { Required course } \\
\%(n)\end{array}$ & $\begin{array}{c}\text { Required } \\
\text { practicum \% (n) }\end{array}$ & $\begin{array}{l}\text { Required part of a } \\
\text { course \% (n) }\end{array}$ & $\begin{array}{c}\text { Elective course } \\
\% \text { (n) }\end{array}$ & $\begin{array}{c}\text { Other means of } \\
\text { delivery \% (n) }\end{array}$ \\
\hline Allied Health & UG & $34 \%(17)^{*}$ & $12 \%(6)^{*}$ & $64 \%(32)^{*}$ & $24 \%(12)^{*}$ & $62 \%(3 I)^{*}$ \\
\hline Allied Health & PG & $0 \%(0)^{\dagger}$ & $0 \%(0)^{* *}$ & $57 \%(4)^{\dagger}$ & $43 \%(3)^{* * *}$ & $29 \%(2)^{\dagger}$ \\
\hline Dentistry & UG & $0 \%(0)$ & $0 \%(0)$ & $100 \%(6)$ & $0 \%(0)$ & $50 \%(3)$ \\
\hline Medicine & UG & $0 \%(0)$ & $0 \%(0)$ & $66 \%(2)$ & $0 \%(0)$ & $67 \%(2)$ \\
\hline Medicine & PG & $22 \%(2)$ & $11 \%(1)$ & $22 \%(2)$ & $22 \%(2)$ & $89 \%(8)$ \\
\hline Nursing & UG & $9 \%(3)^{\ddagger}$ & $6 \%(2)^{\ddagger}$ & $66 \%(2 I)^{\ddagger}$ & $3 \%(1)^{\ddagger}$ & $56 \%(18)^{\ddagger}$ \\
\hline Nursing & PG & $14 \%(1)$ & $0 \%(0)$ & $43 \%(3)$ & $14 \%(I)$ & $29 \%(2)$ \\
\hline \multicolumn{2}{|c|}{ Total (all program types) } & $20 \%(23)$ & $8 \%(9)$ & $61 \%(70)$ & $17 \%$ (19) & $58 \%(66)$ \\
\hline
\end{tabular}

UG $=$ undergraduate; $P G=$ postgraduate; $* 3$ no response; $\uparrow 2$ no response; $\ddagger 1$ no response 
Table 4: Teaching Methods for IPV Content by Program Type

\begin{tabular}{|c|c|c|c|c|c|}
\hline Program Type & Level & $\begin{array}{c}\text { Problem-based IPV } \\
\text { Scenario \% } \\
\text { (n) (\# no response) }\end{array}$ & $\begin{array}{c}\text { Standardized Patient } \\
\text { IPV Scenario \% } \\
\text { (n) (\# no response) }\end{array}$ & $\begin{array}{c}\text { Other simulated } \\
\text { learning \% } \\
\text { (n) (\# no response) }\end{array}$ & $\begin{array}{c}\text { Use of IPV-specific } \\
\text { materials \% } \\
\text { (n) (\# no response) }\end{array}$ \\
\hline Allied Health & UG & $63 \%(27)(10)$ & $28 \%(I I)(13)$ & $68 \%(28 / 4 I)(12)$ & $79 \%$ (33) (II) \\
\hline Allied Health & PG & $20 \%(I)(4)$ & $17 \%(1)(3)$ & $50 \%(3)(3)$ & $50 \%(3)(3)$ \\
\hline Dentistry & UG & $25 \%(1)(2)$ & $75 \%(3)(2)$ & $50 \%(2)(2)$ & $100 \%(4)(2)$ \\
\hline Medicine & UG & $50 \%(I)(I)$ & $50 \%(I)(1)$ & $50 \%(I)(I)$ & $100 \%(2)(1)$ \\
\hline Medicine & PG & $40 \%(2)(4)$ & $20 \%(I)(4)$ & $33 \%(2)(3)$ & $17 \%(1)(3)$ \\
\hline Nursing & UG & $42 \%(8)(14)$ & $14 \%(3)(12)$ & $47 \%(9)(14)$ & $90 \%(17)(14)$ \\
\hline Nursing & PG & $25 \%(1)(3)$ & $25 \%(1)(3)$ & $75 \%(3)(3)$ & $80 \%(4)(2)$ \\
\hline \multicolumn{2}{|c|}{ Total (all program types) } & $50 \%(4 I)(38)$ & $26 \%(21)(38)$ & $59 \%(48)(38)$ & $76 \%(64)(36)$ \\
\hline
\end{tabular}

$U G=$ undergraduate $P G=$ postgraduate

eral test or exam (not IPV-specific) (45\%); and verbal reports by learners (51\%). Respondents were also asked whether there were any procedures in place to evaluate the quality of IPV education provided in their program overall. Approximately half (51/103, 17 no response) reported that there were.

\section{Summary of Collected Curricula}

Curricula received from respondents were analyzed using a template designed for this purpose (available from the authors). Across all program areas, only 10 course curriculum descriptions ( 8 from college programs), one training manual and various PowerPoint presentations were available for review. Many programs at the university level stated that they did not posses formal, written curricula for the IPV content provided within a part of a course, therefore the curricula reviewed tended to outline separate courses that were specific to violence.

In general, review of this sample confirmed the survey results regarding the scope of IPV content and the methods for content delivery (lectures, simulated patients, guest experts, etc.). Some courses included all forms of family violence (i.e., child abuse, elder abuse and IPV), while others focused solely on IPV. Some courses included special topics (like violence among individuals with disabilities, violence within the workplace, the role of the media, women's health and social policy). A few courses included examination - from a number of theoretical perspectives - of broader socio-political structures that influence both the perpetration of violence and policy responses to it.

Courses varied in how they evaluated student learning; two included a general test or examination with the inclusion of IPV questions, three had an essay with IPV available as an optional topic and one course required an IPVspecific essay. Other forms of evaluation not identified as IPV-specific were: student and group presentations, online assignments, resource development, journal or reflective exercises, media clip assessment and volunteer work.

\section{Discussion}

In Ontario, significant variability exists across program areas regarding the methods for IPV education, its delivery and evaluation. While over $80 \%$ of undergraduate allied health and nursing programs provide at least some IPVrelated education, fewer than half of undergraduate medicine and dentistry programs reported providing this kind

Table 5: Instructional Tools and Resources for Delivering IPV Content

\begin{tabular}{|c|c|c|c|c|c|}
\hline Program Type & Level & $\begin{array}{c}\text { Training on facultyl } \\
\text { department goals } \\
\%(n)\end{array}$ & $\begin{array}{l}\text { Support to attend } \\
\text { IPV conferences } \\
\%(n)\end{array}$ & $\begin{array}{c}\text { Opportunities for } \\
\text { collaboration } \\
\%(n)\end{array}$ & $\begin{array}{c}\text { Budget for IPV } \\
\text { materials } \\
\%(n)\end{array}$ \\
\hline Allied Health & UG* & $41 \%(20)$ & $78 \%(38)$ & $86 \%(42)$ & $65 \%(32)$ \\
\hline Allied Health & PG & $0 \%(0)$ & $22 \%(2)$ & $22 \%(2)$ & $11 \%(1)$ \\
\hline Dentistry & UG & $50 \%(3)$ & $66 \%(4)$ & $83 \%(5)$ & $50 \%(3)$ \\
\hline Medicine & UG & $0 \%(0)$ & $33 \%(1)$ & $66 \%(2)$ & $66 \%(2)$ \\
\hline Medicine & PG** & $50 \%(4)$ & $25 \%(2)$ & $88 \%(7)$ & $25 \%(2)$ \\
\hline Nursing & UG* & $21 \%(6)$ & $59 \%(17)$ & $72 \%(21)$ & $38 \%$ (II) \\
\hline Nursing & PG & $29 \%(2)$ & $14 \%(1)$ & $43 \%(3)$ & $29 \%(2)$ \\
\hline \multicolumn{2}{|c|}{$\begin{array}{l}\text { Total } \\
\text { (all program types) ( } 9 \text { no response) }\end{array}$} & $32 \%(35)$ & $59 \%(65)$ & $74 \%(82)$ & $48 \%(53)$ \\
\hline
\end{tabular}

UG = undergraduate; $P G=$ postgraduate; $*(4$ no response $) ; * * 1$ no response 
Table 6: Impact of Internal and External Influences on IPV Education Provision Across All Programs

\begin{tabular}{|c|c|c|c|c|}
\hline Internal Influences & $\begin{array}{c}\text { Mean } \\
(\text { sd) }\end{array}$ & 'Facilitator' \% (n) & 'Neutral' \% (n) & 'Barrier' \% (n) \\
\hline a. Availability and access to instructors who teach IPV content & $1.65(0.97)$ & $81.0 \%(85)$ & $12.4 \%(13)$ & $6.7 \%(7)$ \\
\hline b. Adequate instructor preparation for teaching IPV content & $1.96(1.16)$ & $72.4 \%(76)$ & $13.3 \%(14)$ & $14.3 \%(15)$ \\
\hline c. The instructor's commitment to IPV content & $\mathrm{I} .4 \mathrm{I}(0.73)$ & $91.3 \%(94)$ & $5.8 \%(6)$ & $2.9 \%(3)$ \\
\hline $\begin{array}{l}\text { d. Access to instructors with specific IPV-related expertise/research } \\
\text { endeavours }\end{array}$ & $2.03(1.17)$ & $65.1 \%(69)$ & $24.5 \%(26)$ & $10.4 \%(11)$ \\
\hline e. Faculty/department commitment to IPV education & $1.91(0.99)$ & $69.8 \%(74)$ & $24.5 \%(26)$ & $5.7 \%(6)$ \\
\hline f. Valid and relevant faculty/department mission or goals related to IPV & $2.44(1.36)$ & $53.5 \%(53)$ & $23.2 \%(23)$ & $23.2 \%(23)$ \\
\hline g. Opportunities for curriculum renewal/revision & $1.63(0.96)$ & $82.9 \%(87)$ & $11.4 \%(12)$ & $5.7 \%(6)$ \\
\hline h. Culture of the faculty/department & $1.71(0.85)$ & $78.4 \%(80)$ & $19.6 \%(20)$ & $2.0 \%(2)$ \\
\hline i. Receptiveness of education recipients to IPV content & $1.58(0.78)$ & $88.6 \%(93)$ & $9.5 \%(10)$ & $1.9 \%(2)$ \\
\hline j. Funding allocation for IPV education & $3.07(1.46)$ & $37.0 \%(37)$ & $21.0 \%(21)$ & $42.0 \%(42)$ \\
\hline k. Access to resources to deliver IPV related content (e.g. A/V equipment) & $1.73(1.10)$ & $80.0 \%(84)$ & $10.5 \%(11)$ & $9.5 \%(10)$ \\
\hline $\begin{array}{l}\text { I. Adequate amount of time to include IPV content in curriculum } \\
\text { (length of program) }\end{array}$ & $2.78(1.39)$ & $44.8 \%(47)$ & $19.0 \%(20)$ & $36.2 \%(38)$ \\
\hline \multicolumn{5}{|l|}{ External Influences } \\
\hline a. Current political climate in your institution & $\mathrm{I} .83(0.95)$ & $77.4 \%(82)$ & $15.1 \%(16)$ & $7.5 \%(8)$ \\
\hline b. Current political climate more broadly & $2.12(1.12)$ & $64.2 \%(68)$ & $23.6 \%(25)$ & $12.3 \%(13)$ \\
\hline c. Health care restructuring & $2.66(1.27)$ & $39.8 \%(39)$ & $33.7 \%(33)$ & $26.5 \%(26)$ \\
\hline d. Accreditation & $2.08(1.08)$ & $63.9 \%(62)$ & $26.8 \%(26)$ & $9.3 \%(9)$ \\
\hline e. Licensing body approval process & $2.11(1.16)$ & $58.7 \%(54)$ & $30.4 \%(28)$ & $10.9 \%(10)$ \\
\hline f. External funding & $2.83(1.43)$ & $38.5 \%(37)$ & $21.9 \%(21)$ & $39.6 \%(38)$ \\
\hline
\end{tabular}

Responses on a 5-point scale: ' $I$ ' = facilitator to ' 5 ' = barrier; facilitator = responses of ' $I$ ' or ' 2 ', neutral = responses of ' 3 ', barrier $=$ responses of ' 4 ' or ' 5 '

of education, while the proportions for postgraduate programs were generally lower. This suggests that physicians, one of the key types of HCPs encouraged to intervene in cases of IPV [14], may not have sufficient educational opportunities in their primary training to become adequately knowledgeable, clinically competent, or comfortable in assessing and responding to IPV $[27,29,37]$. The same can be said for other allied health care professionals represented in this sample.

In terms of specific IPV content, all programs providing IPV education reported covering a general overview of the issue, its risk factors, characteristics of victims and perpetrators and information regarding local community resources; this finding is consistent with the literature in this area $[27,40]$. The average teaching time spent on these topics across all program areas ranged from one to four hours per year. Some program areas also reported teaching about identifying and responding to IPV. Given the generally limited curricular content (usually $<4$ hours), and the fact that many programs reported no formal evaluation (nor in most cases credit or acknowledgement) of what students learned in this area, little is known regarding the uptake of this knowledge and whether or not it influences clinical practice. This lack of rigorous evaluation has been cited as an important gap in knowledge $[27,37]$, with the result that evidence-based clinical core competencies for caring for abused women remain unknown [37].
Significant variability existed in the methods for IPV education delivery in this sample. Across programs, the most common approach to including IPV content in the curriculum was as a required component of a course, or delivery of content through regular or occasional workshops, and less commonly, using distance or online techniques. In terms of what this means for future HCPs, specific cases can be used to illustrate key points. For example, the small proportion of postgraduate medical programs with required IPV education means that only $11 \%$ of (4 of 36 responding) programs required medical postgraduate trainees to receive any IPV education. On the other hand, $63 \%$ of allied health undergraduate programs had required IPV education. While resourcing and other barriers may explain why some areas lag well behind others in formalizing their offerings in this area, findings such as these highlight the fact that providing IPV content is still generally ad-hoc and informal. Although integrated, longitudinal, multi-disciplinary and experiential approaches to IPV education as advocated by experts in this area $[20,27,30,38]$ may be emerging in some programs, they are not yet evident, with one exception ${ }^{\mathrm{ii}}$, in Ontario's postsecondary institutions.

The ability to provide content consistently in any area will depend on the availability of expert, or at least knowledgeable, faculty. Program areas reported differing degrees of resource support - including availability of fullversus part-time faculty - for IPV education. Allied health and nursing programs generally reported more material 
support, including budget to acquire IPV-specific educational materials and access to necessary AV equipment. While our cross-sectional data do not allow inferences regarding whether access to appropriate faculty and resources impacts how IPV education is delivered, this is an important area for further study.

Many program areas, especially medicine and nursing, stated that there are multiple competing core educational interests that may make IPV content less of a priority than other areas. When asked what kinds of factors facilitate IPV education delivery, access to instructors with IPV expertise, opportunities for curriculum renewal and content receptiveness within the department and among learners were key influences. Respondents identified lack of funding and lack of adequate time for IPV content in the curriculum as important barriers. External influences on IPV education included the current political climate within the institution, and more broadly, health care restructuring and accreditation, as well as licensing approval processes.

Results from our review of available curricular documents may shed some light on how 'formalized' IPV content is within these programs. The fact that we received few curricular documents may suggest that IPV content is viewed as a component of more widely ranging courses. This may indicate that it is offered in a less formal and structured way, as also reflected in the common statement from respondents that IPV content is present but not in the form of written, formalized syllabi. However the fact that we received so few documents makes it difficult to provide firm conclusions regarding this issue. These results are consistent with surveys of nursing [31] and medical [30] programs. According to the survey by Alpert and colleagues [30], 86\% of medical school deans reported inclusion of IPV-related content in their curricula, but only $55 \%$ of their medical students reported awareness of this topic as part of their courses. The extent to which lack of a more formal curricular status for IPV content may be related to fewer resources and, perhaps, less student focus, warrants further consideration.

\section{Limitations \& Future Research}

This survey was conducted in one jurisdiction within a publicly-funded health care system, and with the majority of responding programs being from publicly-funded or assisted post-secondary institutions. However our excellent response rate, and the fact that the sampling frame was in fact the entire population of relevant programs, leads us to believe that the results provide a reasonable description of the state of IPV education for students training to be health care providers in Ontario, and that this result is, at least to some extent, generalizable to other Canadian provinces, and perhaps more broadly.
We intentionally included programs that educate students training to be the types of HCPs who are expected - at least in the discourse of the field - to identify and respond to abuse among their female patients or clients. In making these decisions we may have cast the net too widely - in some cases, respondents who indicated "no" to provision of any IPV content also expressed confusion as to why we would be contacting them in the first place. It may be that some such programs felt incorrectly identified - so much so that they did not feel it even appropriate to respond. However, given our selection criteria, this is an interesting observation in its own right: there may be assumptions made among those advocating for how abused women should be cared for in the health sector that are at odds with the actual practices in this sector. This observation requires further exploration to ensure a better match between what advocates and women expect, and what HCPs and the health system are able to provide.

The cross-sectional nature of our research, and its specific focus, leave unresolved many key questions that require further consideration and evaluation. These include: 1) How much IPV education are students provided relative to other content areas in their primary educational programs? The present survey gives us an idea of what is offered with respect to IPV education, but how this compares to other content areas within each of these programs is not known. 2) What is the relative quality of IPV education provided among the different program areas, within and between program types, and does this lead to any differences in HCP skills and practices the long run? 3) What, specifically, are the core knowledge and skills required by HCPs in the identification, assessment and response to women exposed to violence? 4) What specific training exists at the local level - i.e., within institutions or when professionals receive orientation to new hospitals, clinics or other settings? 5) To what extent do educational administrators (e.g., deans and other leaders within educational institutions) recognize the importance of IPVrelated education in curricula? More broadly, the question remains as to whether and how IPV education delivered in primary educational programs actually improves clinicians' assessment of and response to abused women.

\section{Conclusion}

The present study highlights the gap between expectations often cited in the IPV literature regarding an active and consistent response to abused women from the health care sector, and the realities of health professionals' educational experiences and preparation. If clinicians are expected to appropriately identify and respond to abused women, they must be provided with relevant education. While this is becoming increasingly available in some areas of primary professional education, it is not yet available to all those in training. 
Current literature and expert opinion suggest that health professional training regarding IPV must be multi-faceted, examine key individual and social risk factors correlated with violence and provide insight into special considerations for women of diverse backgrounds and geography $[40,41]$. Programs that can be tailored to the practice context may be most likely to succeed [42]. Brief educational interventions, such as short workshops, have generally, with some exceptions [28], not been shown effective in improving clinicians' recognition of or response to abused patients, though overall knowledge immediately following these interventions does increase $[43,44]$. Our findings, consistent with those of others $[20,27,37]$ indicate that an integrated approach is rarely the case among the more than 200 programs we surveyed in Ontario. Multifaceted training should provide clinicians with the tools to help women and men understand and where possible avoid the risks for IPV, identify IPV when clinical signs and symptoms are present, and intervene (either directly or through community referrals) with women experiencing it, addressing the acute and chronic physical and mental health effects of violence.

IPV education must also consider the context of clinical work settings and address common barriers to IPV assessment and response. A number of educational resources specific to IPV in health care now exist [45], with an emerging emphasis on evaluating programs and curricula as they are implemented. For example, Moscovic et al. [46] randomized medical students to receive either didactic training alone or didactic training plus experiential community-based training among medical students and found that those with the added "real-world" experience felt much better prepared to provide clinical care in this area. The use of new media to improve access for students and practitioners also shows promise $[47,48]$. Finally, some countries have implemented national level training and evaluation to ensure that clinicians in both training and practice have access to education in this area [49].

In short, there is hope; if we consider the field of child abuse education, which was similarly marginalized in health professional education just a few decades ago $[50,51]$ and is now a formal component of most programs [30], then, as Hamberger [27] (p. 223) states "the future shows promise that the next generation of physicians [and other health care providers] will understand and accept IPV and its health effects on their patients as constituting an important health issue that they will comfortably address."

\section{Competing interests}

The authors declare that they have no competing interests.

\section{Authors' contributions}

CNW, HLM and CF conceived of the study and obtained funding. CNW and MT drafted the manuscript. CC over- saw data collection and entry. MT oversaw data cleaning and preparation, assisted by MKF and AL. EJ participated in the design of the study and performed the statistical analysis. MDH and SMJ participated in study design and data interpretation and helped to draft the manuscript. All authors read and approved the final manuscript. McMaster IPV Education Research Team (below) provided guidance regarding the objectives and design of the research.

\section{Additional material}

\section{Additional file 1}

Survey Instrument. The survey instrument used to collect data from the university and college programs participating in the study.

Click here for file

[http://www.biomedcentral.com/content/supplementary/14726920-9-34-S1.pdf]

\section{Acknowledgements}

This project was funded by the Ontario Women's Directorate, Ontario Ministry of Citizenship \& Immigration, under their Violence Against Women Prevention Innovations Fund (March I, 2005 - March 31, 2006). Nadine Wathen is funded by a Canadian Institutes of Health ResearchOntario Women's Health Council New Investigator Award. M. Kinneret Friedman was funded by Queen's University Jean Royce Fellowship. Susan Jack is funded by a Canadian Institutes of Health Research-Institute of Human Development, Child and Youth Health, Reproduction and Child Health New Investigator Award.

The McMaster IPV Education Research Team Members are as follows:

Co-Principal Investigators: C. Nadine Wathen, Ph.D., Assistant Professor, Faculty of Information \& Media Studies, The University of Western Ontario (UWO), London, Ontario; Harriet L. MacMillan, M.D., M.Sc., Professor, Departments of Psychiatry and Behavioural Neurosciences, and of Pediatrics, McMaster University, Hamilton, Ontario; Clare Freeman, CYW, BA, MSW, Executive Director, Interval House of Hamilton-Wentworth, Hamilton, Ontario. Co-Investigators (alphabetical order): Cristina Catallo, RN, BScN, PhD (Cand), School of Nursing, McMaster University; Chiachen Cheng, MD, FRCP(C), MPH, Department of Psychiatry and Behavioural Neurosciences, McMaster University; Kevin W. Eva, PhD, Assistant Professor, Department of Clinical Epidemiology and Biostatistics, McMaster University; Marilyn Ford-Gilboe, RN, PhD, Associate Professor, School of Nursing, UWO; Iris Gutmanis, BSc, BSc (PT), MSc, PhD, Assistant Professor, Department of Epidemiology and Biostatistics, UWO; Mark D. Hanson, MD, MEd, Associate Professor, Department of Psychiatry and Behavioural Neurosciences, McMaster University; Susan Jack, RN, PhD, Assistant Professor, School of Nursing, McMaster University; Ellen Jamieson, MEd, Research Associate, Offord Centre for Child Studies, McMaster University; Barbara Lent, MA, MD, CCFP, FCFP, Associate Professor, Department of Family Medicine, The University of Western Ontario; Patricia McNiven, RM, BSc, MSc, PhD, Associate Professor, Midwifery Education Program (Department of Family Medicine), McMaster University; Daina Mueller, RN, BScN, MSc, Program Manager, Hamilton Public Health and Community Services; Anna Marie Pietrantonio, MSW, RSW, Clinical Specialist, Child Advocacy and Assessment Program, McMaster Children's Hospital; Helen Thomas, RN, BNSc, MSc, Associate Professor, School of Nursing, McMaster University; Jackie Thomas, MD, MS, FRCS(C), Assistant 
Professor, Department of Obstetrics and Gynecology, University of Toronto; Diana Tikasz, MSW, RSW, Coordinator, Sexual Assault/Domestic Violence Care Centre, Hamilton Health Sciences; Ruta Valaitis, RN, PhD, Associate Professor, School of Nursing, McMaster University; Christine Wekerle, PhD, Associate Professor, Faculty of Education, UWO; Ruth Wilson, MD, FCFP, Professor, Department of Family Medicine, Queen's University, Kingston, Ontario; Andrew Worster, MD, Assistant Clinical Professor, Division of Emergency Medicine, McMaster University.

The authors thank the representatives of the colleges and universities who took the time to complete the survey, and Elaine Ashton, Gisela Auclair, Emily Bonnell, Pearl Dodd, Gloria Jennett, Peggy McAlpine, Lesley Moisey, Dorothy Morgan, Gwen Wong and Stephanie Wong for their efforts in data collection and management, and project support.

iFigures from the Ontario Government http://www.gov.on.ca; the College of Nurse of Ontario: http://www.cno.org/about/index.htm; the Ontario Health Human Resources Tool Kit http://www.healthforceontario.cal upload/health\%20human\%20resources\%20toolkit.pdf; and the Ontario College of Social Work and Social Services Work http://www.ocswssw.org/

iiThe Faculties of Health Sciences (Schools of Medicine, Nursing, and Rehabilitation Therapy) and Law at Queen's University in Kingston, Ontario have been implementing and evaluating multi-disciplinary, integrated IPV education.

\section{References}

I. Tjaden P, Thoennes N: Full report of the prevalence, incidence and consequences of violence against women: Research report Washington, DC: National Institute of Justice; 2000:7I.

2. Krug EG, Dahlberg LL, Mercy JA, Zwi AB, Lozano L, Eds: World report on violence and health Geneva: World Health Organization; 2002.

3. Statistics Canada: Family violence in Canada: A statistical profile 2002 Canadian Centre for Justice Statistics: Ottawa; 2002:89.

4. Coker AL, Smith PH, Bethea L, King MR, McKeown RE: Physical health consequences of physical and psychological intimate partner violence. Arch Fam Med 2000, 9:45I-457.

5. Campbell J, Jones AS, Dienemann J, Kub J, Schollenberger J, O'Campo $\mathrm{P}$, Carlson Gielen A, Wynne C: Intimate partner violence and physical health consequences. Arch Intern Med 2002, 162(10): II57-1163.

6. Plichta SB: Intimate partner violence and physical health consequences: Policy and practice implications. J Interpers Violence 2004, I 9(I I): 1296-1323.

7. Golding JM: Intimate partner violence as a risk factor for mental disorders: A meta-analysis. J Fam Violence 1999, I 4(2):99-132.

8. Mechanic MB: Beyond PTSD: Mental health consequences of violence against women. J Interpers Violence 2004, I 9(II): I 283-1289.

9. Wathen CN, Jamieson E, Wilson M, Daly M, Worster A, MacMillan $\mathrm{HL}$ : Risk indicators to identify intimate partner violence in the emergency department. Open Med 2007, I (2e I I 3-22 [http:/ /www.openmedicine.ca/article/view/63/62].

10. Centers for Disease Control and Prevention, National Centre for Injury Prevention and Control: Costs of IPV against women in the United States. Centre for Disease Control and Prevention. Atlanta (GA) 2003 [http://www.cdc.gov/ncipc/pub-res/ipv cost/ipv.htm]

II. Ulrich YC, Cain KC, Sugg NK, Rivara FP, Rubanowice DM, Thompson RS: Medical care utilization patterns in women with diagnosed domestic violence. Am J Prev Med 2003, 24:9-15.

12. Wisner CL, Gilmer TP, Saltzman LE, Zink TM: Intimate partner violence against women: Do victims cost health plans more? J Fam Pract 1999, 48(6):439-443.

13. Corley MC, Goren S: The dark side of nursing: Impact of stigmatizing responses on patients. Scholarly Inquiry for Nursing Practice: An International Journal 1998, I 2(2):99-I 17.
14. Council on Scientific Affairs, American Medical Association: Violence against women: relevance for medical practitioners. JAMA 1992, 267(23):3184-3189.

15. El-Bassel N, Gilbert L, Witte S, Wu E, Gaeta T, Schilling R, Wada T: Intimate partner violence and substance abuse among minority women receiving care from an inner-city emergency department. Women Health Iss 2003, 13:16-22.

16. Wathen $\mathrm{CN}$, MacMillan $\mathrm{HL}$ : Interventions for violence against women: Scientific review. JAMA 2003, 289:589-600.

17. Nelson HD, Nygren P, Mclnerney Y, Klein J: Screening women and elderly adults for family and intimate partner violence: A review of the evidence for the U.S. Preventive Services Task Force. Ann Intern Med 2004, I 40:387-396.

18. Ramsay J, Richardson J, Carter YH, Davidson LL, Feder G: Should health professionals screen women for domestic violence? Systematic review. BMJ 2002, 325:314-327.

19. U. S. Preventive Services Task Force: Screening for family and intimate partner violence: Recommendation statement. Ann Intern Med 2004, 140(5):382-386.

20. Alpert E): Addressing domestic violence: the (long) road ahead. Ann Intern Med 2007, I47(9):666-667.

21. Sugg NK, Thompson RS, Thompson DC, Maiuro R, Rivara FP: Domestic violence and primary care. Arch Fam Med 1999, 8:30I-306.

22. Moore ML, Zaccaro D, Parsons LH: Attitudes and practices of registered nurses toward women who have experienced abuse/domestic violence. JOGN Nurs 1998, 27(2): 175-182.

23. Thompson RS, Meyer BA, Smith-Dijulio K, Caplow MP, Maiuro RD Thompson DC, Sugg NK, Rivara FP: A training program to improve domestic violence identification and management in primary care: Preliminary results. Violence Vict 1998, 13(4):395-410.

24. Dowd MD, Kennedy C, Knapp JF, Stallbaumer-Rouyer J: Mothers' and health care providers' perspectives on screening for intimate partner violence in a pediatric emergency department. Arch Pediatr Adolesc Med 2002, I 56(8):794-799.

25. Heinzer MV, Krimm J: Barriers to screening for domestic violence in an emergency department. Holist Nurs Pract 2002, 16(3):24-33.

26. Cox E: Synergy in practice: Caring for victims of intimate partner violence. Crit Care Nurs $Q$ 2003, 26(4):323-330.

27. Hamberger LK: Preparing the next generation of physicians: Medical school and residency-based intimate partner violence curriculum and evaluation. Trauma Violence Abuse 2007, 8(2):2।4-225.

28. Lo Fo Wong S, Wester F, Mol SS, Lagro-Janssen TL: Increased awareness of intimate partner abuse after training: a randomised controlled trial. Br J Gen Pract 2006, 56(525):249-257.

29. Gutmanis I, Beynon C, Tutty L, Wathen CN, MacMillan HL: Factors influencing identification of and response to intimate partner violence: A survey of physicians and nurses. BMC Public Health 2007, 7:12.

30. Alpert El, Tonkin AE, Seeherman AM, Holtz HA: Family violence curricula in U.S. medical schools. Am J Prev Med 1998, I 4(4):273-282.

31. Ross MM, Hoff L, Coutu-Wakulczyk G: Nursing curricula and violence issues. J Nurs Educ 1998, 37(2):52-60.

32. Narayan AP, Socolar RR, St Claire K: Pediatric residency training in child abuse and neglect in the United States. Pediatrics 2006, I I 7(6):2215-2221.

33. Blair $M$, Wallace $C$ : Violence in society: nursing faculty respond to a health care epidemic. J Nurs Educ 2002, 4 I (8):360-362.

34. Brandt EN Jr: Curricular principles for health professions education about family violence. Acad Med 1997, 72(I Suppl):S5I-58.

35. Hill JR: Teaching about family violence: $A$ proposed model curriculum. Teach Learn Med 2005, 17(2):169-178.

36. McGibbon EA, McPherson CM: Interpretive pedagogy in action: Design and delivery of a violence and health workshop for baccalaureate nursing students. J Nurs Educ 2006, 45(2):8I-85.

37. Institute of Medicine, Committee on Training Needs of Health Professionals to Respond to Family Violence, Cohn F, Salmon M, Stobo JD, Eds: Confronting Chronic Neglect. The Education and Training of Health Professionals on Family Violence Washington, DC: National Academy Press; 2002 
38. Hamberger LK, Phelan MB: Domestic violence screening and intervention in medical and mental health-care settings. New York: Springer; 2004.

39. Dillman D: Mail and internet surveys: The tailored design method 2nd edition. New York, NY: John Wiley Company; 200I.

40. Short LM, Johnson D, Osattin A: Recommended components of health care provider training programs on intimate partner violence. Am J Prev Med 1998, I 4(4):283-288.

4I. Humphreys C: $\mathbf{A}$ health inequalities perspective on violence against women. Health Soc Care Community 2007, I5(2): I20-127.

42. Bonds DE, Ellis SD, Weeks E, Palla SL, Lichstein P: A practice-centered intervention to increase screening for domestic violence in primary care practices. BMC Fam Pract 2006, 7:63.

43. Coonrod DV, Bay RC, Rowley BD, Del Mar NB, Gabriele L, Tessman TD, Chambliss LR: A randomized controlled study of brief interventions to teach residents about domestic violence. Acad Med 2000, 75(I):55-57.

44. Haist SA, Wilson JF, Lineberry MJ, Griffith $\mathrm{CH}$ : A randomized controlled trial using insinuated standardized patients to assess residents' domestic violence skills following a two-hour workshop. Teach Learn Med 2007, I 9(4):336-342.

45. Cory J, DeChief L: The SHE Framework: Safety and health enhancement for women experiencing abuse 2008 [http://www.bcwomens.ca/Serv ices/HealthServices/WomanAbuseResponse/Resources.htm]. Vancouver: BC Women's Hospital \& Health Care

46. Moskovic CS, Guiton G, Chirra A, Núñez AE, Bigby J, Stahl C, Robertson C, Thul EC, Miller E, Sims A, Sachs CJ, Pregler JP: Impact of participation in a community-based intimate partner violence prevention program on medical students: a multicenter study. J Gen Intern Med 2008, 23(7): 1043-7.

47. Harris JM Jr, Kutob RM, Surprenant Z], Maiuro RD, Delate TA: Can Internet-based education improve physician confidence in dealing with domestic violence? Fam Med 2002, 34(4):287-292.

48. Emergency Department Response to Domestic Violence [http://www.dveducation.ca/welcome.php]

49. Shefet $D$, Dascal-Weichhendler $H$, Rubin $O$, Pessach N, Itzik $D$, Benita S, Ziv A: Domestic violence: a national simulation-based educational program to improve physicians' knowledge, skills and detection rates. Med Teach 2007, 29(5):el33-8.

50. Chang A, Oglesby AC, Wallace HM, Goldstein H, Hexter AC: Child abuse and neglect: physicians' knowledge, attitudes, and experiences. Am J Public Health 1976, 66( I 2): I |99-I20I.

51. Woolf A, Taylor L, Melnicoe L, Andolsek K, Dubowitz H, De Vos E, Newberger E: What residents know about child abuse: Implications of a survey of knowledge and attitudes. Am J Dis Child 1998, I42(6):668-672.

\section{Pre-publication history}

The pre-publication history for this paper can be accessed here:

http://www.biomedcentral.com/1472-6920/9/34/prepub
Publish with Bio Med Central and every scientist can read your work free of charge

"BioMed Central will be the most significant development for disseminating the results of biomedical research in our lifetime. "

Sir Paul Nurse, Cancer Research UK

Your research papers will be:

- available free of charge to the entire biomedical community

- peer reviewed and published immediately upon acceptance

- cited in PubMed and archived on PubMed Central

- yours - you keep the copyright
BioMedcentral 